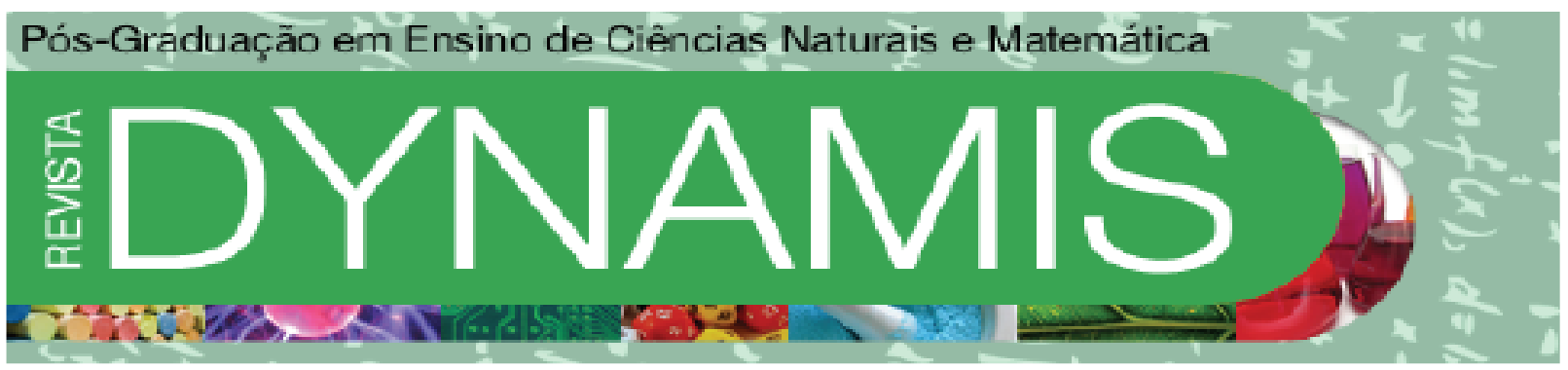

\title{
CIÊNCIA, TECNOLOGIA E SOCIEDADE PARA A FORMAÇÃO CIDADÃ DOS LICENCIANDOS EM QUÍMICA, FÍSICA E MATEMÁTICA
}

SCIENCE, TECHNOLOGY AND SOCIETY FOR TRAINING COLLEGE STUDENTS IN CHEMISTRY, PHYSICS AND MATHEMATICS.

\section{Tatiana Comiotto}

Doutora em Educação Científica e Tecnológica

Professora do Programa de Pós-Graduação em Ensino de Ciências, Matemática e Tecnologia Departamento de Química - Universidade Estadual de Santa Catarina comiotto.tatiana@gmail.com

Ivanete Zuchi Siple

Doutora em Engenharia de Produção

Professora do Programa de Pós-Graduação em Ensino de Ciências, Matemática e Tecnologia Departamento de Matemática - Universidade Estadual de Santa Catarina

ivanete.siple@udesc.br

Ivani Teresinha Lawall

Doutora em Engenharia Mecânica

Professora do Programa de Pós-Graduação em Ensino de Ciências, Matemática e Tecnologia Departamento da Física - Universidade Estadual de Santa Catarina ivani.lawall@udesc.br 
Tatiana Camiotto, Ivanete Zuchi Siple, Ivani Teresinha Lawall, Maria da Graça Moraes Braga Martin, Lorena Silva de Andrade Dias

\section{Maria da Graça Moraes Braga Martin}

Doutora em Química

Professora do Programa de Pós-Graduação em Ensino de Ciências, Matemática e Tecnologia

Departamento de Química

Universidade do Estado de Santa Catarina

maria.martin@udesc.br

Lorena Silva de Andrade Dias

Licencianda de Matemática

Acadêmica do Curso de Licenciatura em Matemática

Universidade do Estado de Santa Catarina

lorena.andradedias@gmail.com 


\title{
Resumo
}

Este artigo aborda uma perspectiva para a formação de um profissional cidadão, tendo como alicerce o enfoque da Ciência, Tecnologia e Sociedade (CTS). Apresenta algumas concepções teóricas sobre Educação, CTS e Formação, as quais fundamentarão as análises posteriores, constituindo-se desta forma, um conjunto de princípios essenciais e opiniões sistematizadas que tem como proposição explicar, elucidar, interpretar ou unificar um dado domínio de fenômenos ou de acontecimentos que se oferecem à atividade prática nos cursos de licenciatura. Procura, também, apresentar a relação que existe entre a Educação e sua influência no ensino da Ciência, da Tecnologia e dos aspectos Sociais, suas interligações possíveis e necessárias para a formação dos futuros graduandos dos cursos de licenciatura em química, física e matemática. Ainda, considera o desafio dos docentes que buscam meios adequados - a fim de preparar os acadêmicos para a pluralidade dos ambientes sociais - que deles exigem competências que relacionem teoria e prática que, em uma das propostas nos cursos de licenciatura, é realizado por meio das disciplinas de Laboratórios de Ensino, que privilegiam a ação e discussão da alfabetização científica e tecnológica.

Palavras-chave: Educação; Ciência, Tecnologia e Sociedade; Licenciatura; Docência.

\begin{abstract}
This article deals with the training of people with a focus on Science, Technology and Society - STS. We will present some theoretical conceptions about education, STS and training, which will be the basis for the subsequent analysis, which will in turn constitute a set of core principles and systematic opinions whose purpose is to explain, clarify, interpret or unify a given phenomena domain or events that offer practical activities in college education. We will also present the relationship between education and its influence on the teaching of Science, Technology and Society, and possible and necessary interconnections for the training of future graduates from degree programs in chemistry, physics and mathematics. It also considers the challenge of teachers who seek adequate means - in order to prepare academics for the plurality of social environments - that require of them skills that relate theory and practice that, in one of the proposals in the degree programs, is realized through the disciplines of Teaching Laboratories, which privilege action and discussion of scientific and technological literacy.
\end{abstract}

Key words: Education; Science, Technology and Society; College Education; Teaching. 


\section{INTRODUÇÃO}

Os desafios da atualidade e os vindouros que a humanidade irá se deparar serão incomensuráveis. Assim, há uma decisiva busca pelo desenvolvimento de modelos de produção e de geração de renda, que venham contribuir para o mínimo impacto ambiental aceitável e que contribua para o atendimento das demandas públicas e, também, da redução da desigualdade social (MENESTRINA, 2008).

Formar apenas para atender o mercado de trabalho é contribuir para a manutenção dos problemas sociais, pois as necessidades do mercado, em ampla escala, promulgam contradições e conflitos do sistema econômico e político. O profissional formado em uma universidade deve sim, realizar ações que beneficiem a sociedade com a qual interage e, também, aprender a resolver problemas concretos, utilizando as suas competências e conhecimentos científicos e tecnológicos (DECLARAÇÃO DE BUDAPESTE, 1999).

A formação acadêmica, independentemente da área de atuação, "necessita oportunizar ao estudante a capacidade de reconhecer os problemas relevantes de seu entorno" (MENESTRINA, 2008, p.41), avaliando distintas posições em relação a ele e de maneira consciente, atuar junto à sociedade. Desta forma, será abordado neste artigo uma perspectiva para a formação de um profissional cidadão tendo como alicerce o enfoque da Ciência, Tecnologia e Sociedade (CTS), apresentando algumas concepções sobre Educação, Licenciatura, CTS e formação cidadã.

\section{PERCORRENDO UMA TRAJETÓRIA MIL VEZES REVISITADA}

Sinalizam-se, aqui, algumas concepções, a fim de esclarecer pontos de vista a respeito dos paradigmas educacionais, dos cursos de licenciatura em ciências, da epistemologia da construção do conhecimento em Educação e as concepções de CTS. A Educação é uma prática social, que ocorre em épocas históricas, constituída por ideologias particulares e cercada por subjetividades. Faz parte da Sociedade, está vinculada aos seus objetivos e interligada à formação do cidadão que dela compartilha (FREIRE, 2011). Constitui-se como um campo especial para o desenvolvimento, a partir do momento que oportuniza o aperfeiçoamento do pensar para encarar os novos desafios. Menestrina (2008) afirma que:

\footnotetext{
A afinidade entre a produção do conhecimento, seu aproveitamento tecnológico e a necessária rapidez solicitada por estes processos conduziu a um deslocamento na função educacional. É imperativo transformações na forma como o conhecimento é alcançado, desenvolvido e comunicado (MENESTRINA, 2008, p.29).
}

Atualmente, as discussões sobre os cursos de formação de professores (licenciaturas) estão relacionadas a problemas complexos, uma vez que a Educação faz parte de um contexto que está interligado com as indefinições e incertezas da sociedade. É neste cenário que são necessárias ações em termos de qualidade educacional como superação do quadro vigente. $\mathrm{O}$ país deparou-se com o processo de globalização em diferentes aspectos: tecnológico, econômico, político, cultural e educacional. Tais fatores vêm proporcionando expressivas alterações na formação em nível universitário. A fim de que essas atitudes avancem, são 
fundamentais os estudos e pesquisas que problematizem o pensar e o fazer didático-pedagógico, de forma a redimensionar a função das tecnologias e das diferentes linguagens no processo de formação (MENESTRINA, 2008). Para estes novos tempos, o ensino deve ser visto

\footnotetext{
Como instrumento de transformação e enriquecimento do conhecimento, dando aos seres humanos a possibilidade de modificar sua vida social e atribuir um maior sentido à coletividade de experiência humana. Para isso, deve ser pensado observando o mundo atual e interferindo de forma positiva na realidade brasileira. (FRONZA, 2016, p. 241).
}

Educação origina-se de dois vocábulos latinos - educare (que significa orientar, nutrir, decidir num sentido externo, conduzindo o sujeito de onde ele encontra-se até o local onde deseja estar) e educere (faz referência a necessidade de promoção do aparecimento do interior para o exterior das potencialidades que o ser humano tem) (MENESTRINA, 2008). Estas conceituações estão relacionadas às diferentes correntes pedagógicas que as formularam, bem como a posturas culturais e políticas que motivaram seu desenvolvimento (GRINSPUN, 1994). Desta forma, percebem-se diversos caminhos em que a Educação está caracterizada como "uma rede de conhecimentos entremeada por intencionalidades e ações que são postas em prática para sua efetivação" (MENESTRINA, 2008, p.30). Ao refletir sobre a Educação, acredita-se que sua aplicação deva estar voltada a compreender o sujeito como um ser histórico, palpável e legítimo. Além disso, deve estar introduzido em seu contexto intrínseco, conforme a visão de mundo, os valores e práticas sociais de uma cultura particular (FREIRE, 2011).

Independente do espaço e situação, o ser humano está relacionado ao processo educativo. Desta forma, não é possível pensar e praticar Educação separadamente do processo de produção e do projeto de Sociedade que se pretende. É necessário que a Educação se volte para o real a fim de transformar o ser humano. A Educação, espaço de reflexões críticas, desvenda-se como um ambiente fundamental para essas reflexões. É possível averiguar que em muitos níveis de ensino há uma preocupação em relação a construção de projetos que gerem a emancipação e uma maior abrangência dos segmentos sociais frente à Ciência e a Tecnologia (MENESTRINA, 2008).

Nos atuais dias, é possível perceber o contrassenso do desenvolvimento científico/tecnológico convivendo com intensas crises sociais. Em inúmeras ocasiões, devido a questões burocráticas, quando os modelos se desvelam como insuficientes para responder aos aspectos da complexidade social, aparece uma sensação de desorientação e apatia frente às reflexões mais necessárias, abarcando todos os campos do fazer humano. Percebe-se, então, uma série de transformações em diferentes segmentos e áreas da sociedade quer geográficos, políticos, históricos ou culturais. A Educação é, pois, um meio pelo qual é possível modificar este panorama.

O desenvolvimento de uma sociedade não é estabelecido linearmente. É essencial a construção de um projeto no qual aconteça a conscientização dos que a integram e instrumentos viáveis de alterações práticas nesta sociedade. Este é o papel da Educação: arquitetar e participar deste projeto, de forma contextualizada considerando as causas e os acontecimentos que ocorrem diariamente. Segundo Grisnspun (1994), mesmo que seja inconveniente, é inevitável a existência de um rompimento nas relações desse contexto. 
Foram observadas, em várias pesquisas na área educacional - entre elas Schön (1987), Tardif (1991), Gamboa (2007), Pereira (2011), Gasparin (2005) e Lemke (1997) -, que as ações educativas envolvem diferentes tipos de conhecimentos, aspectos pedagógicos, concepções, organizações da relação ensino e aprendizagem, análise das estruturas de tempo e espaço, expectativas de transformação, avaliação das demandas sociais, políticas e ideológicas, habilidades de conversão dos materiais didáticos de diferentes saberes acumulados entre outros processos específicos que necessitam ser considerados (SOLBES; VILCHES, 1997). Com o passar do tempo, as ações educacionais, vão se alterando, pois, as concepções de homem, do mesmo modo, se transformam, interferindo diretamente no modo de pensar e agir a respeito das diferentes problemáticas existentes no contexto social, político, cultural e ambiental.

As concepções e os sentidos atribuídos por cada sujeito, assim como aqueles construídos pela coletividade são constituídos através da cultura acumulada na Sociedade, através de crenças compartilhadas, dos valores e das experiências, das referências históricas e culturais e dos estudos e pesquisas. O conjunto das concepções pessoais configura a memória coletiva e estabelece a identidade da própria Sociedade. O sujeito possui diferentes visões de mundo, que podem ser categorizadas, fundamentalmente, em dois conjuntos segundo Norton (1991):

a) Uma visão fragmentada e dissociada - neste ponto de vista, o ser humano tem a tendência a minimizar as explicações, a simplificá-las, a fazer previsibilidade, perdendo a sua essência e o seu significado e, nesse sentido, desvirtuando-se da realidade. Conforme essa visão se almeja continuamente os mesmos resultados para as mesmas causas. Perde-se a visão do todo, das relações e do conjunto. Esta atitude tem sido conveniente, para muitos, para explicar o mundo até hoje;

b) Uma visão integradora - atrelada a diversos fatores, em que tudo está acoplado às relações e por esse motivo nada é previsível ou determinista. É um sistema complexo, onde se procuram ultrapassar a ruptura e as barreiras entre as práticas, os saberes e a vida. Esta visão compõe-se dos conhecimentos fortificados a partir de experiência, de subsídios, de saberes e de padrões de pensamento perpassados através de gerações e transmitidos pela tradição, pela Educação e pela comunicação social, sendo preparado conjuntamente e partilhado entre distintos grupos.

Nesse sentido, o ensino deve oferecer condições para que os universitários se tornem sujeitos de sua própria história, sobretudo por meio da participação e do compromisso com a Sociedade. Assim, a universidade transcende o papel de formadora exclusiva para a profissão e faz com que os acadêmicos vivenciem possibilidades com vistas a um desenvolvimento integral, abrangente e completo, possibilitando a eles a internalização de valores como os de democracia e justiça, essenciais para sua participação coletiva. Ainda, de acordo com Fronza, no ensino é preciso "perceber que, para além dos aspectos de formação técnica, há de se considerar os de ordem social. Perceber, questionar e levar à reflexão sobre a importância da retomada de uma sociedade que considere o coletivo, o outro, a humanidade e a solidariedade" (FRONZA, 2016, p. 206).

Quando são considerados os discursos de filósofos, políticos, economistas e sociólogos acerca das questões científicas e tecnológicas, pode-se verificar que este debate está difundido no cotidiano. A despeito da abundância de interpretações que o tema Ciência e Tecnologia suscitam e dos significados que ele incorpora, há um alicerce comum, a partir do momento em que se encontram na mesma base paradigmática. Os antigos paradigmas, em termos educacionais, no entanto, tornaram-se incapazes de lidar com as constantes mudanças ocorridas na sociedade (HARVEY, 2001): as informações se tornaram muito volumosas e inacessíveis 
para um número significativo da população, gerando um aumento da complexidade em todos os setores da vida profissional e pessoal. Portanto, há a necessidade de se estabelecer interrelacionamentos entre campos de conhecimento anteriormente estanques, bem como provocar mudanças no sistema valorativo e no comportamento social. Promover condições de empregabilidade atualizando permanentemente os profissionais que, devido à quantidade de novas informações disponível em novos formatos e com novas formas de acesso, ficam à margem do mercado de trabalho.

Segundo Menestrina (2008, p. 33), "uma Educação que prioriza um conhecimento regulatório, conservador das dinâmicas sociais vigentes e de mercado não reflete a necessidade de mudança e um conhecimento que se proponha emancipatório". Quando se observam as abordagens contemporâneas de ensino, identifica-se que o ato de aprender decorre de ponderações sobre o que está sendo ensinado, para que está sendo ensinado e de que maneira este ensino irá interferir em como o sujeito atua na sociedade, contradizendo, assim, a concepção tradicional de um ensino que enfatiza a aquisição do conhecimento e somente depois se aprende a empregá-lo. Aprende-se quando há reflexão sobre o que está sendo aprendido. Isso sugere a necessidade de problematizar os conteúdos a serem aprendidos para entender o sentido que possuem. Para isso, torna-se indispensável que o conhecimento, através da ciência e da tecnologia, seja disponibilizado nas diversas áreas do conhecimento e demanda o domínio de habilidades na esfera das distintas linguagens de maneira a buscar e reter o significado que está intrínseco ao saber.

O ensino pode ser compreendido como experiências de aprendizagem, organizado de forma a contemplar o desenvolvimento do estudante, a fim de desafiar limites pré-estabelecidos e almejar novas possibilidades com vistas à transformação da ordem social. Deve estabelecerse, também, como tomada de decisões sobre o que os estudantes precisam aprender, constituindo-se em princípios de aprendizagem, formas de incentivo a novas aprendizagens, através de estratégias motivadoras, seleção de conteúdos interessantes, processo de avaliação compatível com os objetivos previamente estabelecidos, relação professor-estudante e estudante-estudante que envolva parcerias e articulação permanente entre a teoria e a prática (KUENZER, 2000). Também, pode-se entender o ensino como um meio de gerar enriquecimento e mudança no conhecimento, permitindo que a vida social seja modificada e que ao sentido de coletividade seja atribuído maior valor (FRONZA, 2016).

A inclusão das atividades ditas "complementares", previstas pelas Diretrizes Curriculares, dão a oportunidade ao educando de obter experiências expressivas que lhe tragam a habilidade para refletir sobre a amplitude dos problemas do cotidiano, a partir da vivência e dos conhecimentos produzidos. Assim, as universidades, juntamente com os acadêmicos, passam a ser responsáveis por uma formação compromissada com as necessidades regionais, nacionais e mundiais. Os estudantes passam a ser os sujeitos da própria aprendizagem, que é caracterizada por novas maneiras de comunicação, produção de habilidades diversificadas e competências. Pinheiro, Silveira e Bazzo (2007) defendem um ensino que não aponte para uma formação estritamente técnica (formação do profissional), todavia que oportunize a reflexão das implicações políticas, econômicas, sociais e ambientais dos produtos destas áreas técnicas (Tecnologia). Assim, é necessário que a Educação

Se ocupe com a formação do cidadão crítico e competente, preocupado, para além do trabalho propriamente dito, com o ambiente e meio em que está situado e que integre conhecimentos em prol de uma sociedade menos desigual. Uma educação que defenda 
um sistema coletivo de humanidade em detrimento de um sistema pautado no consumismo mercantilizado (FRONZA, 2016, p. 201).

O debate sobre as mudanças da sociedade atual incide no esgotamento dos velhos paradigmas. Isto, igualmente, se reflete nas concepções de Ciência e Tecnologia. É nesta circunstância que discussões a respeito de CTS têm se destacado, notadamente nas últimas décadas e vêm delimitando a constituição de currículos de cursos de licenciatura relacionados com as ciências em todo o mundo (BENNETT et al., 2013).

Verifica-se que depois da Segunda Guerra Mundial dois cenários na universidade começaram a se afastar: o das ciências e o das humanidades. As ciências se encontravam em elevação e asseguravam, com seus conhecimentos exatos e sua conversão em Tecnologia benéfica, à vida prática, a solução de todas as dificuldades, como se fosse possível extinguir a dor e o sofrimento, buscando desenvolvimento e o conforto. A competência das áreas humanas era de constante precaução a respeito das comprováveis implicações sociais do emprego da Ciência e da Tecnologia. Esta crítica é reforçada por Morin (2000) que de tal modo afirma:

[...] efetivou-se a separação entre a cultura humanística que nutria a inteligência geral e a cultura científica que, por vezes de modo hermético, encontra-se compartimentalizada entre as disciplinas. A falta de comunicação entre as duas culturas traz consigo graves consequiências para uma e outra. A cultura humanista revitaliza as obras do passado, a cultura científica valoriza apenas aquelas adquiridas no presente. A cultura humanista é uma cultura geral que, através da filosofia, do ensaio e da novela, coloca problemas humanos fundamentais e incita à reflexão. A cultura científica suscita um pensamento consagrado à teoria, mas não uma reflexão sobre o destino humano e o destino da própria ciência (MORIN, 2000, p.12).

Ao abordar a concepção de Ciência, Tecnologia e Sociedade (CTS), é preciso que esta seja analisada através de uma visão de mundo integradora e dinâmica, pois ela permite lidar com a complexidade das relações entre os homens, em distintas escalas espaciais e temporais, caracterizando uma postura epistemológica ampla, fundamentada na construção e reconstrução permanente da própria visão e das concepções delas decorrentes.

Discutir ciência, tecnologia e sociedade instiga ampliar este campo de conhecimento e encontrar, nas instituições responsáveis pela educação tecnológica, espaço para relacionar as reflexões ao contexto educacional, mostrando os desafios e perspectivas que se apresentam no processo civilizatório ${ }^{1}$ (FRONZA, 2016, p.13).

Assim, a CTS é uma construção coletiva ao longo do tempo, do espaço e das relações que a estabelecem; sendo responsável, também, pela articulação dos diversos elementos da totalidade científica, tecnológica e social na qual atua. Ciência, Tecnologia e Sociedade é o resultado e a resultante da Educação, que influencia e recebe influências da sociedade, da

\footnotetext{
${ }^{1} \mathrm{O}$ processo civilizatório é, de acordo com Fronza (2016, p. 34), uma “perspectiva histórica de mudanças com evolução e avanço social e cultural, que afeta os modos de ser e de viver dos seres humanos, interferidos pelos impactos causados por causa das evoluções e revoluções, inclusive tecnológicas sobre a sociedade, levando-a a passar por transições contínuas”.
} 
cultura e das particularidades psicológicas individuais (conscientes e inconscientes), e dos pensamentos com as quais se associa direta ou indiretamente (MENESTRINA, 2008).

\section{A FORMAÇÃO CIDADÃ DO LICENCIANDO EM QUÍMICA, FÍSICA E MATEMÁTICÁ}

A formação cidadã do licenciando foco deste artigo, refere-se à inserção dos acadêmicos nas problemáticas das comunidades e o estabelecimento por eles e pelos demais envolvidos no processo de aprendizagem (professores, pais, técnicos, funcionários...) de laços entre os conceitos abordados em sua licenciatura e as relações que pode se estabelecer entre sua profissionalização e a sociedade. Isso enfraquece as críticas de que muitos universitários passam pela licenciatura sem terem contato prático com a realidade e de não conseguirem construir conhecimentos apropriados para solucionar os problemas sociais mais emergentes.

Este distanciamento dirigiu, por muitos anos, a um entendimento de universidade numa abordagem mais utilitarista, voltada exclusivamente às demandas do mercado, a serviço do desenvolvimento econômico e tecnológico, objetivando um padrão empresarial, e que até mesmo hoje é percebida, infelizmente, em alguns cursos de formação de professores.

O Brasil, assim como demais países, encontra-se em processo de globalização tanto nas questões tecnológicas, econômicas, políticas e culturais, como na área educacional, o que tem causado significativas mudanças nos processos de formação.

As Instituições de Ensino Superior (IES), por vezes, representam e delineiam de maneira incisiva a história, os arranjos de poder e o ambiente político das alianças que as alimentam. É inegável a necessidade atual de se pensar e agir acerca dos cursos de licenciatura em ciências alterando a conjuntura que se apresenta, transformando as ferramentas tecnológicas em instrumentos de empoderamento da sociedade, a fim de oportunizar aos sujeitos a busca de ideais de vida e da coletividade. O palco particular da Ciência e da Tecnologia, bem como de algumas áreas do ensino, demonstram carências, o que torna imperioso o comprometimento de todos os atores envolvidos para modificar os paradigmas vigentes.

Nos cursos de licenciatura em que invariavelmente prevalece o desenvolvimento da Ciência e da Tecnologia, novos encargos são confiados à Universidade, que tem a responsabilidade de formar profissionais de alta qualificação, com a competência de atuar num mercado de trabalho que exige novas e constantes habilidades (STUMP; ZASNICOFF, 1999).

Segundo Colombo (2004) a epistemologia subjacente aos cursos superiores, ainda hoje, é a empirista, em que o conhecimento é percebido como aquele que surge do mundo do objeto (meio físico ou social) tornando, muitas vezes, o estudante apenas um sujeito receptor do conhecimento.

Assim sendo, é imperativa uma reavaliação, pois não há como pensar este modelo em que tanto as licenciaturas como os cursos superiores de modo geral, ainda são demarcados, basicamente, pela fragmentação entre as disciplinas e a separação dos saberes que os originam e resguardam.

É de se esperar que isso conduza a uma efetiva revolução curricular, que ultrapasse meras tentativas de atualizar cursos através do artifício de ajustar peças desconectas do quebra-cabeça curricular. Uma nova concepção filosófica que rompa com os moldes atuais na busca de uma formação mais globalizada duradoura do 
conhecimento pode ser a saída (BAZZO; PEREIRA; LINSINGEN, 2008, p. 45).

Os cursos de licenciatura apresentam-se como uma ação educacional e sociocultural de valor indispensável para o avanço de todas as atividades humanas, tanto singulares como coletivas. Nesse sentido, o ensino só se justifica e tem razão de existir quando estiver profundamente voltado para o aperfeiçoamento e promoção das capacidades humanas e sociais. Ele deve constituir-se em um processo analítico, crítico e dinâmico com vistas ao aperfeiçoamento das condições sociais (MENESTRINA, 2008).

Os cursos superiores precisam ter com função primordial:

\begin{abstract}
A formação de cidadãos capazes de construir uma sociedade mais justa e aberta, mediante um processo de ensino-aprendizagem promotor de análise crítica e visão prospectiva, baseado na vinculação com a sociedade e em atividades de criação intelectual científica, técnica e humanística (SOARES; VIEIRA, 2014, p.166).
\end{abstract}

Conforme Colombo (2004), verifica-se nos cursos de licenciatura, em geral, a necessidade se desenvolver ações transdisciplinares ${ }^{2}$ que ultrapassem as discussões teóricas, indispensáveis para a vida. No momento em que a supremacia da Ciência e da Tecnologia é ventilada, em que as interferências do ser humano na natureza vão expondo seu significado mais decisivo, em que as heterogeneidades sociais estão cada vez mais aparentes e injustas, em que os interesses econômicos particulares ou de pequenas alianças impõem-se aos da sociedade, é imprescindível a apreciação sobre a relação entre os cursos de licenciatura e as demandas econômico-tecnológicos, sob fundamentos assentados a paradigmas socialmente inclusivos.

Em muitos cursos superiores, ainda, nota-se a presença das concepções positivistas da Ciência. Segundo Torres (2002, p. 52), a "finalidade desses cursos é a formação de profissionais que atendam às necessidades do desenvolvimento econômico e tecnológico". A despeito de inúmeras pesquisas serem desenvolvidas em que se percebe a preocupação com o movimento dos cursos de licenciatura, muitas vezes existem apenas ações isoladas e que necessitam uma fundamentação teórico-crítica mais aprofundada em relação à Ciência, à Tecnologia e a Sociedade.

Colombo (2004) traz um questionamento muito pertinente a respeito deste assunto: como é possível formar profissionais criativos, sensíveis e cidadãos, se os professores geralmente fundamentam suas práticas de ensino na repetição e memorização? A transformação exige um repensar sobre a formação docente numa perspectiva contínua e de desenvolvimento profissional, pois pode ser entendida como um processo pessoal, incessante, incompleto, permeando várias áreas formativas. "A formação contínua, portanto, é um fenômeno que ocorre ao longo de toda a vida e que acontece de modo integrado às práticas sociais e às cotidianas escolares de cada um, ganhando intensidade e relevância em algumas delas" (PASSOS et al., 2006, p.195). É essencial até mesmo uma cultura geral para constituir relações em nível

2 TRANSDISCIPLINAR - A definição do conceito de transdisciplinaridade registrada na cartada transdisciplinaridade - UNESCO enfatiza a visão aberta, ultrapassando o campo das ciências exatas devido ao seu diálogo e sua reconciliação não apenas com as ciências humanas, mas também com a arte, a literatura, a poesia e a experiência espiritual. Sommerman (2006, p. 50) ressalta os "eixos básicos da evolução transdisciplinar na Educação: a Educação intercultural e transcultural; o diálogo entre arte e ciência; a integração da revolução informática na Educação; a Educação transpolítica; a relação transdisciplinar: os educadores, os educandos e as instituições e sua metodologia subjacente". 
filosófico-político com a finalidade de compreender a função social de cada um dos espaços de formação do acadêmico.

Falar em formação docente é se reportar à formação do licenciando e no quanto é importante romper com estrutura tradicional de educação que se pauta na repetição do conhecimento. Num currículo que esteja em movimento, essa ruptura pode se dar por meio de reformas, de modo a afugentar a estrutura de transferência, que concebe o conhecimento como algo pronto, acabado e indiscutível (FRONZA, 2016, p. 290).

Nesse sentido, como os cursos de licenciatura nas áreas de ciências exatas mantêm esta estreita relação com a Ciência e a Tecnologia, é necessário propiciar ações que possibilitam o desenvolvimento da alfabetização científica e tecnológica. Isso pode ser feito, segundo Palacios, Galbart e Bazzo (2005), por meio de cursos de pós-graduação ou como complemento curricular para estudantes de diversas áreas, no Ensino Superior. Também, na ótica de Menestrina (2008), por meio de disciplinas optativas, de enxertos nas próprias disciplinas do curso ou mesmo de cursos de extensão. Igualmente, os cursos de licenciatura devem pautar-se pelas experiências já vivenciadas, por atividades criadoras e nas reflexões que propiciem novidades e ações transformadoras (RAZUCK, 2013).

Torna-se fundamental, também, uma revisão sobre os procedimentos metodológicos de ensino e práticas pedagógicas difundidas, nestes cursos de formação de professores, para a consolidação destes objetivos. Entretanto, mais importante que os câmbios metodológicos, pedagógicos, didáticos, curriculares, o essencial é uma mutação epistemológica (MENESTRINA, 2008). Deste modo, os documentos que legiferam sobre o ensino fazem jus à apreciação prudente para averiguar as concepções que são pertinentes a essa área de conhecimento.

\footnotetext{
A formação docente deve ser vista e pautada numa perspectiva que permita uma visão ampla e consciente sobre a sociedade e o progresso pelo qual ela passa. Para isso, a formação teórico-epistemológica é fundamental e dá ao docente uma noção crítica acerca da educação e sua prática (FRONZA, 2016, p. 293).
}

Entende-se que a visão epistemológica, exibida pelos componentes de uma instituição refletem expressivamente as ações que está produz, tendo como implicação alterações nas ações metodológicas. Portanto, a concepção de CTS que se baseia numa raiz epistemológica interiorizada particular e coletivamente, reflete-se de maneira subentendida ou explicita nos processos didático-metodológicos das práticas educativas.

Neste sentido, formar profissionais éticos (VALLS, 2006; VASQUES; PALIPÉRIO, 2003), com visão cultural e humanística, com responsabilidade socioambiental e com envergaduras para projetar e desenvolver produtos, equipamentos e sistemas que proporcionem o avanço da qualidade de vida da população, com a intenção de ampliar mudanças sociais, torna-se imperioso. Para isso, são necessárias pesquisas tecnológicas e científicas em seu campo de atuação e discussões entre as equipes multidisciplinares. É indispensável, também, a discussão sobre o desenvolvimento de formas de produção e de geração de renda, que contribuam para o mínimo de impacto ambiental admissível e que favoreçam o atendimento das demandas coletivas, e de uma diminuição da desigualdade social. 


\begin{abstract}
A articulação dos eixos associados às concepções de mundo, ciência e ser humano que o docente tem, permite a formação de uma visão crítica a respeito do papel desses conceitos no mundo de hoje e o quanto podem favorecer na formação de cidadãos conscientes, autônomos e alfabetizados cientificamente (FRONZA, 2016, p. 302).
\end{abstract}

Em todas as áreas profissionais não se pode pensar numa formação apenas para atender o mercado de trabalho, contribuindo para a manutenção dos problemas sociais, pois as necessidades do mercado, em ampla escala, promulgam contradições e conflitos do sistema econômico e político. O profissional formado deve sim, realizar ações que beneficiem a sociedade com que interage.

\begin{abstract}
No futuro do emprego ou do trabalho, é certo que teremos cada vez menos 'profissões' e cada vez mais 'profissionais'. O foco do mercado de trabalho está em constante evolução para buscar sempre a melhor pessoa, levando em conta toda sua formação humana, e não apenas o aprendizado especificamente técnico.... Hoje, e cada vez mais, é preciso antes de tudo ser. Mas ser o quê? Ser humano.... Para um jovem estudante, é preciso dizer que o futuro que o espera depende menos do mundo e mais dele mesmo. Esse "ser humano", na minha opinião, tem relação direta com as questões sociais que envolvem a formação do cidadão (FRANCO, 2000, p. 111).
\end{abstract}

A formação acadêmica precisa propiciar aos futuros profissionais a competência de identificar os problemas relevantes de seu entorno, aferindo diferentes posturas em relação a eles e de modo consciente, operar junto à sociedade. A abordagem CTS tem sido amplamente reconhecida como meio de alcançar estes objetivos (DASS, 2005).

O perfil desejado para futuro professor, sob o ponto de vista deste artigo e da legislação vigente, portanto, é um profissional capaz de analisar os problemas em sua dimensão global, considerando os aspectos políticos, econômicos, sociais, ambientais e culturais em acolhimento às demandas da sociedade. É esperado que o licenciando tenha visão e compreensão integral dos problemas, no sentido de transformar positivamente a sociedade em que está inserido (FIRME, 2011).

Além disso, é importante também estabelecer um comparativo entre a organização curricular, os objetivos e o perfil do egresso quanto a sua coerência interna no que tange a CTS e constatar de que maneira estão indicadas as ações que favoreçam o desenvolvimento das competências para o desenvolvimento deste licenciando. A formação do acadêmico tem por alvo diplomar os estudantes para que tenham competências de acordo com os conhecimentos adquiridos na vida social, universitária, pessoal e laboral, aparelhando-os para lidar com as incertezas, com a flexibilidade e a aceleração na resolução de problemas durante sua atuação profissional (KUENZER, 1992).

A ampliação de competências é expressa na Lei de Diretrizes e Bases (LDB), demarcando como adequado àquele que "constitui, articula, mobiliza valores, conhecimentos e habilidades para a resolução de problemas não só rotineiros, mas também inusitados em seu campo de atuação" (BRASIL, 1996). Desta maneira, competente é o sujeito que age com eficácia perante o inesperado, dominando o conhecimento acumulado e operando de modo transformador e criativo. Muitas vezes é esperado que apenas uma alteração na metodologia de trabalho favoreça uma modificação de concepções. Nem sempre isso acontece. Por exemplo, podem-se desenvolver práticas didático-pedagógicas com trabalhos em grupos, debates, seminários, 
entretanto, para isso, é possível utilizar um embasamento de conteúdos tradicionais ou até mesmo obter um discurso construtivista e atuar de maneira tecnicista.

É fundamental compreender que existe intencionalidade em todas as atuações, que está gerada na estrutura epistemológica e está inter-relacionada a uma série de crenças, valores, técnicas e interesses, e é interdependente das escolhas efetivadas, do destino onde são implementadas as realizações, assim como do paradigma adotado.

\section{CONSIDERAÇÕES FINAIS}

O desafio, principalmente para os que analisam e se comprometem com as ações educativas, é a indicação de trajetórias adequadas para aparelhar os cidadãos, de distintos segmentos, para coexistirem em ambientes sociais plurais e que isso exige conhecimentos, competências e atitudes invariavelmente articulados em relação a teoria e prática.

Os cursos de licenciatura devem, portanto, propor ações de construção de alternativas. Uma delas é o espaço das disciplinas de Laboratórios de Ensino, presentes nos cursos de formação inicial dos professores, que podem propiciar um espaço privilegiado de ação e discussão de alfabetização científica e tecnológica, podendo ser conectado com outras disciplinas de práticas de ensino e de metodologias e de conteúdos específicos, possibilitando aos acadêmicos uma visão reflexiva e crítica dos saberes que integram e complementam a formação do professor. Para isto, é importante, a proposição de uma visão integradora e transdisciplinar de todos os envolvidos na elaboração de políticas educacionais.

Em decorrência desta mudança de postura, principalmente epistemológica, pode-se atuar mais efetivamente na construção de currículos e programas que conduzam a promoção de reflexões críticas, de investigações e de propostas para a solução dos problemas sociais vigentes. Isto contribuirá de maneira significativa e qualitativa visando a melhoria da qualidade de vida da população.

A visão de CTS diferencia-se como alicerce primordial para consecução das conjecturas teórica e metodológica intrínseca às práticas pedagógicas institucionais que podem gerar mudanças significativas ou apenas reeditar padrões sociais já em vigor. Nesse contexto, é adequado refletir sobre as questões sociais relevantes, o progresso científico - tecnológico além de analisar temas relacionados ao ensino, suas finalidades e princípios tanto em suas características de desenvolvimento pessoal, quanto de incremento social e conhecimento científico-tecnológico. Esta é a provocação: formar profissionais éticos, com concepções cultural e humanística, que possam se responsabilizar socioambientalmente e com competência para gestar planos, produtos, instrumentos e sistemas que propiciem o progresso e o avanço da qualidade de vida da população, na significação mais abrangente, dirigindo-se para a transformação social.

É mister redefinir a função do ensino nos projetos de modernidade, desenvolvendo reflexões sobre o futuro e sobre os engendramentos com os demais segmentos. As atuações devem conectar-se diretamente com a existência humana, da mesma forma que dela dependem. Concordar com esta interdependência é estar comprometido como licenciando e com a formação diversificada dos futuros profissionais, é interpretar o espaço com a finalidade de supervisionar, dar caminhos e concretizar os planos, os desejos, os projetos que são demandados 
Tatiana Camiotto, Ivanete Zuchi Siple, Ivani Teresinha Lawall, Maria da Graça Moraes Braga Martin, Lorena Silva de Andrade Dias

pela coletividade. Essa ação está inter-relacionada à cultura, ao avanço do meio social e as oportunidades para sua concretização.

\section{REFERÊNCIAS}

BAZZO, W. Ciência, Tecnologia e Sociedade e o Contexto da Educação Tecnológica. Florianópolis: Editora da UFSC, 1998.

BAZZO, W. A.; PEREIRA, L. T. V.; LINSINGEN, I. Educação Tecnológica: enfoques para $o$ ensino de engenharia. 2. ed. ver. e ampl. Florianópolis: Ed. da UFSC, 2008.

BENNETT, J., CAMPBELL, B., HOGARTH, S., LUBBEN, F. A Systematic Review of the Effects on High School Students on Context-based and Science-Technology-Society (STS) Approaches to the Teaching Science. Disponível em:

<http://www.york.ac.uk/media/educationalstudies/documents/research/cresj/bennettsaarmste. pdf $>$. Acesso em: 01 abr. 2013.

BRASIL. Lei de Diretrizes e bases da educação. Disponível em: <http://www.planalto.gov.br/ccivil_03/Leis/L9394.htm>. Acesso em: 01 abr. 2013.

COLOMBO, C. R. Princípios teórico-práticos para a formação do engenheiro civil: Em Perspectiva de uma Construção Civil Voltada ao Desenvolvimento Sustentável. Tese de Doutorado em Engenharia de Produção da Universidade Federal de Santa Catarina, Florianópolis - 2004.

DASS, P.M., Using a Science/Technology/Society Approach to Prepare Reform-Oriented Science Teachers: The Case of a Secondary Science Methods Course. Issues in Teacher Education, v.14, n. 1, 2005. Disponível em: < http://www1.chapman.edu/ITE/15dass.pdf >. Acesso em 12 maio 2013.

DECLARAÇÃO DE BUDAPESTE. Marco Geral de ação, 1999. Disponível em: < http://www.unesco.org/science/wcs/esp/declaracion_s.htm > Acesso em: 18 dez. 2010.

FIRME, R. N.; AMARAL, E. M. R. Analisando a implementação de uma abordagem CTS na sala de aula de química. Ciência e Educação, v. 17, N. 2. P.383 - 399, 2011.

FRANCO, S. Farol Alto, São Paulo. Revista Exame, n.1, a. 34, 12 jan. 2000.

FREIRE, P. Pedagogia da Autonomia: saberes necessários à Prática Educativa. 43.ed. Rio de Janeiro: Paz e Terra, 2011.

FRONZA, K. R. K. Repercussões Sociais Decorrentes do Avanço Científico e Tecnológico: manifestações curriculares resultantes da intervenção docente. 2016. Tese (Doutorado em Educação Científica Tecnológica) - Universidade Federal de Santa Catarina, Florianópolis, 2016. 
Tatiana Camiotto, Ivanete Zuchi Siple, Ivani Teresinha Lawall, Maria da Graça Moraes Braga Martin, Lorena Silva de Andrade Dias

GAMBOA, S. S. Pesquisa em Educação: métodos e epistemologias. Chapecó: Argos, 2007.

GASPARIN, J. L. Uma Didática para a Pedagogia Histórico-Crítica. 3ed. Campinas: Autores Associados, 2005.

GRINSPUN, M. P. S. Z. Paradigmas em Educação: avaliação e perspectivas. Ensaio. Rio de Janeiro, Fundação Cesgranrio, v. 1, n 2, jan. mar. 1994.

KUENZER, A. Z. Humanismo e tecnologia numa perspectiva de qualificação profissional. Revista Tecnologia Educacional, Rio de Janeiro, ABT, n 107, 1992.

KUENZER, A. Ensino Médio: Construindo uma proposta para os que vivem do trabalho. São Paulo: Editora Cortez, 2000.

HARVEY, D. Condição pós-moderna. 10ª ed. São Paulo: Loyola, 2001.

LEMKE, J. L. Aprender a hablar ciencia. Barcelona: Paidós, 1997.

MENESTRINA, T. C. Ciência, tecnologia e sociedade e formação do engenheiro: análise da legislação vigente em uma universidade pública estadual. Tese de doutorado. Florianópolis, SC, 2008.

MENESTRINA, T. C. Curso: CTS - uma proposta inovadora. 2008. Disponível em: <www.cts.joinville.udesc.br/arquivos/apostila-cts.doc>. Acesso em: 27 ago. 2016.

MORIN, E. Os sete saberes necessários à Educação do futuro. São Paulo: Cortez, 2000.

NORTON, B.G. Ecological heath and sustentable resource management. New York: Columbia University, 1991.

PALACIOS, E. M. G; GALBARTE, J. C. G; BAZZO, W. Introdução aos estudos CTS (Ciência, Tecnología e Sociedade). Organización de Estados Iberoamericanos (OEI), 2005

PASSOS, C. L. B. et al. Desenvolvimento profissional do professor que ensina Matemática: Uma meta-análise de estudos brasileiros. Quadrante, v. 15, n. 1, p. 193-219, 2006.

PEREIRA, M. V. O lugar da prática na globalização da Educação superior. Educação em Revista Belo Horizonte, v. 27, n. 3, dez. 2011. Disponível em: $<$ http://www.scielo.br/scielo.php?script=sci_arttext\&pid=S0102$46982011000300006 \& \operatorname{lng}=\mathrm{en} \& n r m=i$ iso $>$. Acesso em: 20 out. 2012.

PINHEIRO, N. A. M, SILVEIRA, R. M. C. F. BAZZO, W.A. Ciência, tecnologia e sociedade: a relevância do enfoque CTS para o contexto do ensino médio. Ciência e Educação, v. 13, n. 1, p. 71-84, 2007.

RAZUCK, R. C. S. R.; RAZUCK, F. B. O Enfoque CTS na Formação de Professores em Ciências - Um estudo de caso da Universidade de Brasília. 2013. Disponível em: 
Tatiana Camiotto, Ivanete Zuchi Siple, Ivani Teresinha Lawall, Maria da Graça Moraes Braga Martin, Lorena Silva de Andrade Dias

<http://www.esocite.org.br/eventos/tecsoc2011/cd-anais/arquivos/pdfs/artigos/gt003aeducacao.pdf $>$. Acesso em: 02 fev. 2013

SCHÖN, D. Educating the reflective practitioner: toward a new design for teaching and learning in the professions. 1987. San Francisco: Jossey-Bass.

SOARES, S. R.; VIEIRA, F. Aprendizagem, ensino e desenvolvimento profissional docente na universidade: desafios, perspectivas e trajetórias de mudança. 2014. Disponível em: <http://www.ufrgs.br/inov/docs/educacaoedirhumnumaperspecintercult>. Acesso em: 27 ago. 2016.

SOLBES, J.; VILCHES, A. STS Interactions and the Teaching of Physics and Chemistry. Science Education, v.81, n.4, 1997, p.377-386. Disponível em: <http://peoplelearn.homestead.com/STS.Chem.Physics.pdf >. Acesso em: 01 abr. 2013.

SOMMERMAN, A. Inter ou Transdisciplinaridade? São Paulo: Paulus, 2006, 75p.

STUMP, S.M.D., ZASNICOFF, L.S. Considerações sobre a formação de engenheirosprofessores do curso de mestrado em engenharia elétrica. IN: Anais do VI Encontro de Ensino de Engenharia, Itaipava, RJ, 1999.

TARDIF, M.; LESSARD, C.; LAHAYE, L. Os professores face ao saber: esboço de uma problemática do saber docente. Teoria \& Educação. Porto Alegre, Pannonica, n.4,1991, p. 215-233.

TORRES, S.R. A formação de docentes da engenharia e processos de mudanças: contribuições para a formação de professores. Tese (Doutorado em Psicologia da Educação) - Pontifícia Universidade Católica de São Paulo (PUC), São Paulo - 2002.

VALLS, A.L.M. O que é ética. Coleção Primeiros Passos. São Paulo: Brasiliense, 2006.

VASQUES, M. H. B.; PALIPÉRIO, F. C. M. C. Educação: Pluralidade, Ética e Competência na Formação Profissionalizante Continuada dos Educadores. 2003. Disponível em: <http://lms.ead1.com.br/upload/biblioteca/modulo_1934/2DOZLE50IU.pdf >. Acesso em: abr. 2013. 